\title{
The Socio-Ecological Dynamics of Food Insecurity among Subsistence-Oriented Indigenous Communities in Amazonia: a Qualitative Examination of Coping Strategies among Riverine Communities along the Caquetá River, Colombia
}

\author{
Carlos A. Torres-Vitolas ${ }^{1}$ (D) - Celia A. Harvey ${ }^{2,3} \cdot$ Gisella S. Cruz-Garcia $^{4,5}$ - Martha Vanegas-Cubillos ${ }^{4}$. \\ Kate Schreckenberg ${ }^{6}$
}

Published online: 8 June 2019

(C) The Author(s) 2019

\begin{abstract}
Despite the Amazon's natural wealth, food insecurity is a major concern among indigenous communities. Yet, little is known about the socio-ecological dynamics shaping the contributions of local ecosystems to food security. In this study we examine how ecological features interact with normative structures, lifestyles, and livelihoods to expose indigenous peoples to food shortages and how they attempt to cope with worsening food insecurity conditions through participatory exercises with ten indigenous communities along the Caquetá River, Colombia. Our results indicate that traditional food systems are sensitive to human and natural capital disruptions. However, severe food insecurity is prevented by the combination of a well-preserved environment and traditional social institutions, which facilitates widespread access to wild foods, farmland, environmental knowledge, supportive relations, and labour. Nevertheless, traditional adaptations appear insufficient when food insecurity results from health shocks. Our findings highlight the need for interventions that pursue conservation objectives whilst promoting social structures supporting resilience.
\end{abstract}

Keywords Coping strategies · Food insecurity · Subsistence agriculture $\cdot$ Hunting and gathering · Indigenous communities · Amazon · Colombia $\cdot$ Caquetá River

\section{Introduction}

Food insecurity, defined as the lack of "secure access to sufficient amounts of safe and nutritious food for normal growth

Carlos A. Torres-Vitolas

c.torres-vitolas@imperial.ac.uk

1 School of Public Health, Imperial College London, Saint Mary's Campus, London W2 1PG, UK

2 Betty \& Gordon Moore Center for Science, Conservation International, 2011 Crystal Drive, Suite 500, Arlington, Virginia, USA

3 Monteverde Institute, Monteverde, Puntarenas, Costa Rica

4 Decision and Policy Analysis Research Area, International Center for Tropical Agriculture, km 17 Recta-Cali Palmira, Apartado Aéreo 6713 Cali, Colombia

5 Sowing Diversity = Harvesting Security, Oxfam Novib, Postbus 30919, The Hague 2500 GX Den Haag, Netherlands

6 Department of Geography, King's College London, 30 Aldwych, London WC2B 4BG, UK and development and an active and healthy life" (FAO 2017: 107), remains a global problem. Currently, 815 million people endure chronic undernourishment worldwide (FAO 2017). In a context of growing concern about climate change, the United Nations' Sustainable Development Goals demand signatory countries to end hunger whilst preserving ecosystems (UN 2015). There is consensus that further research is needed to better understand the role natural ecosystems may play in developing sustainable and resilient food systems that benefit vulnerable populations, such as the poor, women, and indigenous populations (Cruz-Garcia et al. 2016; Poppy et al. 2014; Powell et al. 2015; Sunderland et al. 2013).

There is substantive evidence that wild foods and other non-timber forest products (NTPFs) support the regular functioning of food and livelihood systems among the rural poor, generating 'daily net' contributions in various forms that enhance dietary diversity and nutritional intake (Powell et al. 2015; Shackleton and Shackleton 2004; Sunderland et al. 2013). In this regard, studies in tropical forest settings have shown that rural indigenous communities are more likely to consume a varied diet than those mostly relying on market 
purchases or farm produce (Piperata et al. 2011; Roche et al. 2007; van Vliet et al. 2015). Natural ecosystems can also indirectly support regular access to food by facilitating livelihood diversification. Key resources, such as fuelwood or fresh water, and foods, like fruits and vegetables, can be freely obtained from the wild, allowing poor families to free up resources to enrich their diets through market purchases. Moreover, abundance of natural resources can foster income-generation activities, ranging from eco-tourism to fishing and hunting, which enhance purchasing power for food and other commodities (Cruz-Garcia et al. 2016; van Vliet et al. 2014).

Natural ecosystems can also strengthen the resilience of food systems by offering a 'safety net' to those experiencing shocks such as health emergencies or natural hazards through the provision of nutritious resources in the form of wildplants, insects, or bushmeat (Powell et al. 2015; Pramova et al. 2012) and additional income through sales resources such as timber or game (McSweeney 2004; Pattanayak and Sills 2001; Takasaki et al. 2004). Furthermore, it has been argued that uncultivated plants and trees can be more resilient to climate variability than many cultivated crops, potentially reducing the impact of damaging climate events (Pramova et al. 2012).

However, elucidating the specific roles that natural ecosystems may play in preventing food insecurity remains a challenge. Food insecurity is not a condition with well-delimited boundaries but rather comprises a gradient of worsening conditions, ranging from worrying about food or being unable to eat ones' favourite foods, to hunger and famine, which may occur under a variety of timescales, from transitory to chronic (FAO 2016, 2017). In this context, examining nature's contributions as part of either a 'daily' or 'safety' net appears insufficient, given that similar practices and resources can play both roles depending on the type of event being experienced. Among forest dwellers, for instance, harvesting wild vegetables not only constitutes a daily activity but can also reflect deteriorating levels of food availability depending on the volume, quality, and social acceptability of the items being collected (Paumgarten et al. 2018; Powell et al. 2015). Moreover, in the context of adaptation to climate change, both notions intermingle. Current uses of natural resources as insurance mechanisms are expected to shape communities' future daily uses of NTFPs, as associated natural hazards become more frequent and communities gradually adopt measures to manage risk (Berman et al. 2012; Eriksen et al. 2005). Examinations of natural ecosystems' contributions to mitigating food insecurity therefore need a comprehensive account of the resources and practices people resort to under a variety of food insecurity scenarios (Powell et al. 2015; Pramova et al. 2012).

Likewise, researchers need to look beyond the direct food contributions from natural ecosystems to assess the sustainability of existing strategies against food insecurity, since strong dependence on nature-based insurance and livelihood strategies can sometimes operate as 'poverty traps' (Paumgarten et al. 2018; Pramova et al. 2012) that lead to increased vulnerability to covariate shocks, such as floods or droughts. The stresses from such shocks may not only force people to dispose of their assets to survive but can also lead to a spike in the rates of extraction of valuable natural resources. The latter not only reduces the availability of NTFPs but also further exposes residents to natural hazards due to ecosystem degradation or mismanagement (Ferse et al. 2014; Richardson 2010). Furthermore, even when natural capital is abundant and accessible, vulnerable groups, like the extreme poor or the elderly, customarily lack the assets base necessary to collect sufficient volumes and varieties of forest resources (Pattanayak and Sills 2001; Paumgarten et al. 2018; Paumgarten and Shackleton 2011) or to invest in activities that can generate high returns (e.g., costs of transporting NTFPs to markets) (McSweeney 2004; Pattanayak and Sills 2001).

This study contributes to ongoing debates regarding the role of natural ecosystems in helping communities to deal with food insecurity by examining the socio-ecological dynamics affecting regular access to food among rural indigenous communities living in well-preserved parts of the Colombian Amazon, in the Caquetá river basin. We address two issues. First, the extent to which traditional adaptations to the environment that support local food systems may simultaneously render residents vulnerable to diverse forms of food insecurity. Second, the factors that shape the final benefits local residents may accrue from natural ecosystems when coping with food scarcity events.

We purposively selected the study area to illustrate a socioecological configuration associated with beneficial ecosystem contributions to food systems (Powell et al. 2015; Sunderland et al. 2013) since the communities enjoy substantive forest cover ( $>90 \%)$, low population density, favourable rights of access to forests and rivers, and minimal presence of marketoriented extractive activities (Fontaine 2008; Ramirez-Gomez et al. 2015; Sánchez-Cuervo et al. 2012). Together these conditions give rise to an 'ideal' case-scenario (Yin 2008) that serves to ascertain the role (and limitations) of natural ecosystems in ensuring food security among those groups whose food and livelihood systems are well-adapted to their environment (Paumgarten et al. 2018; Paumgarten and Shackleton 2011).

This study is relevant to socio-ecological settings in which communities pursue subsistence-oriented livelihoods in biodiversity-rich rainforest areas, chiefly in Amazonia. We argue that there is a pressing need for in-depth examinations of the human-nature interactions shaping food insecurity in such settings. Whilst there have been recent efforts to promote related policy debates in response to environmental change due to urbanisation, deforestation, and pollution (Ortiz et al. 2013; UNEP 2009), such discussions commonly overlook the plight of communities yet to be directly affected by these 
trends (Kuhnlein et al. 2013). Food insecurity is in fact a constitutive part of indigenous populations' reality. For example, Brazil's and Colombia's health and demographic surveys from 2009 and 2011 found, in their respective Amazonas departments, that stunting ${ }^{1}$ rates among children under five were over twice their country-level estimates (Brazil: $40.8 \%$ against 7.1\%; Colombia: $28.7 \%$ against 13.2\%) (Horta et al. 2013; Ojeda et al. 2011). In addition, hydrological data indicate that severe flooding and droughts periodically occur in Amazonia, exposing residents to covariate shocks (Marengo et al. 2013). Climate models suggest that seasonal weather patterns are changing in the region, reporting a gradual intensification and lengthening of the dry-season (Joetzjer et al. 2013); while conservation models highlight that biodiversity-rich areas may face extinction threats originating elsewhere, as intensive deforestation can produce knock-on effects on sensitive mammalian species (Soares-Filho et al. 2006).

We examine food insecurity through indigenous groups' own descriptions of disturbances affecting access to food and the response mechanisms they adopt. We use the concept of 'coping strategies,' defined as the range of responses that people adopt temporarily in the face of stressors or shocks that take place within existing social structures, such as production, knowledge, and governance systems (Ellis 2003; Eriksen et al. 2005). These structures include those institutionalised forms of adaptation to the environment that help managing risk, known as 'adaptive strategies' (Berman et al. 2012; Eriksen et al. 2005). Accounts of coping behaviours are considered suitable indicators of food insecurity. Comparisons across countries found that coping strategies reflect worsening food insecurity conditions, as people attempt to balance their food needs with income generation and assets preservation (Davies 1993; Harvey et al. 2014; Maxwell et al. 2008). When food insecurity is mild, for instance, families typically draw on existing resources (e.g., wild foods). However, as scarcity worsens, unsustainable means of accessing food become increasingly prevalent, like selling durable assets. Survival strategies such as begging or skipping meals signal failure to cope. The range and times in which such responses are adopted, moreover, are considered to reflect sensitivity and resilience to food insecurity (Davies 1993; Ellis 2003). A rapid transition towards harsh measures in the face of short-term shocks, for example, indicates a highly sensitive livelihoods system, as in the case of landless casual labourers, who may rapidly experience hunger when unemployed for a few days. In turn, the absence of destitution-type coping strategies despite experiencing shocks indicates that a food system can recover fast enough to prevent the collapse of local livelihoods.

We frame our examination in the sustainable livelihoods framework (Scoones 1998) and privilege a qualitative lens

\footnotetext{
${ }^{1}$ Children are considered stunted if their height-for-age ratio is over two standard deviations below the WHO Child Growth Standards.
}

to account for the socio-cultural structures guiding residents' food provision activities, which are then defined not only in economic terms but also in relation to lifestyles and forms of identity (Rigg 2007). This approach helps to broaden our understanding of livelihoods from a set of measurable stocks of money, labour, and goods to one that incorporates immaterial forms of capital, such as social relations and forms of association (social capital) (Bebbington et al. 2006) as well as traditional knowledge (cultural capital) (Reyes-García et al. 2008). We pay particular attention to the position of indigenous communities at the interface between different institutional settings: the traditional rules that govern community life and those of the wider political economy, which rule the State and markets. This circumstance can be critical since indigenous peoples' capacity to profit from NTFPs may face formal restrictions, like conservation laws (UNEP 2009; van Vliet et al. 2014), or informal hurdles, such as social discrimination (Kuhnlein et al. 2013; van Vliet et al. 2014).

\section{Study Area}

The study was conducted in the corregimiento La Pedrera, department of Amazonas, Colombia. ${ }^{2}$ It comprises four indigenous reserves (resguardos), containing ten villages, two informal rural settlements (veredas), La Pedrera town, and two State forest reserves (Fig. 1). The region experienced substantive population growth in recent decades. Colombia's 1985 census reported 1631 inhabitants while that of 2005 found 3267 residents. Official projections estimated 4700 inhabitants by 2013 (DANE 2011). The corregimiento's area is 394,944 ha (Ramirez-Gomez et al. 2015) so population density remains low (0.012 persons/ha). Yucuna, Macuna, Tanimuka, and Miraña ethnicities live in shared lands around La Pedrera town. The Yukuna are aboriginal to the region. Other groups arrived in the late nineteenth century as forced labour for the natural rubber industry. Since the 1940s, others have arrived attracted by availability of fertile land, presence of primary schools, and growing trade in the town market (Van der Hammen 1992).

Average annual temperatures range from $26.1^{\circ} \mathrm{C}$ to $26.6{ }^{\circ} \mathrm{C}$ and annual rainfall averages 3100 to $3500 \mathrm{~mm}$ (IDEAM 2014a, b). Over $90 \%$ of the corregimiento is covered by natural forest, with no significant deforestation observed in the past decade (Sánchez-Cuervo et al. 2012). Two seasons are observed: dry (September - March) and rainy (April - August). The Caquetá river's levels and discharges are at their highest during June July ( $\left.9 \mathrm{~m}, 15.37 \mathrm{~m}^{3} / \mathrm{s}\right)$ and lowest around January-February (4 m, $4.83 \mathrm{~m}^{3} / \mathrm{s}$ ) (IDEAM 2015). Severe climate events periodically occur. Droughts were documented in 1996, 2005, and 2011 and severe floods in 2004 and 2012. During droughts,

\footnotetext{
${ }^{2}$ Corregimientos are a sub-division of a department that encompass small rural populations. Unlike municipalities, they have no elected town council.
} 


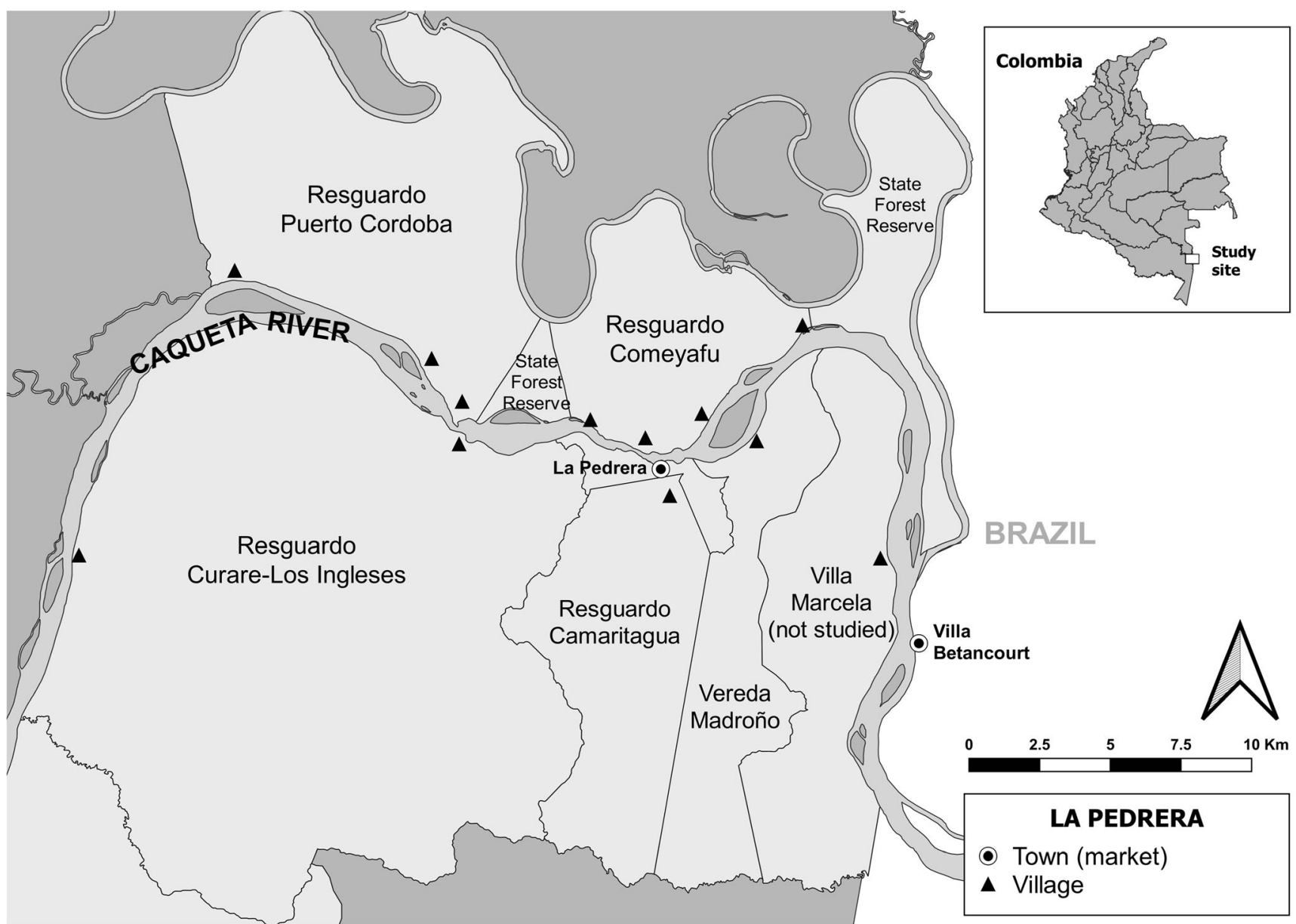

Fig. 1 Corregimiento La Pedrera, Colombia

discharges may decrease $40 \%-50 \%$ below average and during unusually wet periods they may increase $30 \%$ to $80 \%$ above average (IDEAM 2015; Marengo et al. 2013).

Villages lack electricity, water, or sanitation services. Primary schools service villages but secondary education is only available in town. Governance structures are based around community-level authorities: Resguardos were legally established between 1985 and 2002. They constitute territories ceded by the State to communities, under a collective ownership arrangement, and managed by traditional authorities. Veredas, established in the 2000s, are administrative areas formally under the corregimiento's jurisdiction but are in fact managed by community boards.

Residents mainly pursue subsistence livelihoods, centred on slash-and-burn agriculture, prevalent in the region since preColumbian times (Arroyo-Kalin 2012), fishing, hunting, and foraging (Ramirez-Gomez et al. 2015; Van der Hammen 1992). Different types of farmland (chagras) are cultivated: (i) upland plots; (ii) lowland plots; (iii) flood-plains; and (iv) river islands. Floodplains, islands, and lowland chagras are cultivated only during the dry season, being under water the rest of the year. Inter-cropping is predominant, usually including tubers - mainly cassava — and fruits — chiefly bananas and pineapples. Farm produce is largely for household consumption. Productive land is neither sold nor rented. Within resguardos land is communal. Chagras are assigned by authorities to community members. In the veredas, plots are undocumented and claims are based on historical occupation and recognition by community-boards.

Fishing and hunting are also mostly for household consumption, although occasional sales are common. Catfish species, like dorado (Brachyplatystoma flavicans) and pintadillo (Pseudoplatystoma tigrinum), and white-lipped peccaries (Tayassu pecari) and tapirs (Tapirus terrestris) are sold in the town market. Bushmeat trading is illegal but widely accepted. Apart from some households that rear poultry, livestock is nonexistent. The extraction of timber for shelter is common in the region but its commercialisation is limited. Foraging of wild fruits is mostly for subsistence and ritual use. Paid farm labour is non-existent. When required, households rely on collaborative agreements (mingas) in which friends and neighbours provide labour in return for food, drinks, and mambe (roasted coca leaves). The few forms of remunerated non-farm labour reported include (i) non-professional services (e.g., cooks), (ii) administrative work for public or civil organisations (e.g., schools or NGOs), and (iii) being a member of a village authority. Apart from the last, employment is usually short-term. 
Residents had previously experienced periods of greater market integration associated with certain forms of natural resource extraction temporarily prevalent in different decades (fur trading in the 1970s, timber extraction in the 1980s and 1990s as the town-market expanded due to expanding fishing and mining activities). Presently, La Pedrera remains a source of freshwater fish for Colombia's urban markets (RamirezGomez et al. 2015; Van der Hammen 1992). Perceived biodiversity and income losses after these industries lost momentum, however, motivated resguardos and veredas to adopt conservation measures to support traditional livelihoods since the early 2000 s. In collaboration with the NGO Conservation International, communities have formulated natural-resource management plans that include a zoning scheme, dividing communities' territories into use and conservation areas (excluded from daily foraging, hunting, and fishing), a system of quotas for the extraction of thatch, timber, and game, and a ban on fishing practices using large nets, dynamite, or poison. These measures are perceived to have preserved wildlife and aided recovery of some native plants (Ramirez-Gomez et al. 2015).

\section{Methods}

Data were obtained using participatory methods between March and June 2013. Three thematic group exercises were conducted on (i) local livelihoods, (ii) diets, and (iii) coping strategies for food insecurity (Schreckenberg et al. 2016). During group discussions on livelihoods, participants described predominant living conditions, economic activities, domestic roles, and seasonality issues. They also produced a socioeconomic classification of residents using local criteria. During discussions of diets, participants jointly produced a list of food items consumed locally, identifying their sources. These exercises provided contextual information for subsequent descriptions of food shortages and coping mechanisms.

Discussions on coping strategies were adapted from Maxwell and colleagues (Maxwell and Caldwell 2008; Maxwell et al. 2008). Participants described common events limiting normal access to food and the strategies households adopt to deal with them. Food scarcity events were grouped into 'severity scenarios' representing the extent to which households' diets were affected. These served to identify which bundles of coping strategies were most commonly adopted according to different levels of worsening conditions. Finally, participants described the resources mobilised for each coping behaviour and the (in)formal rules affecting their implementation.

Ten villages participated in the study. ${ }^{3}$ Five were interviewed separately and the remainder were clustered into two groups due to their shared access to forest areas and similar livelihoods. Twenty-seven discussion groups were conducted

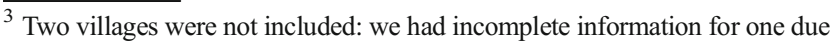
to time constraints, the other declined to participate.
}

(Table 1). A purposive sampling strategy was used for all exercises. Discussion groups on livelihoods aimed to obtain depictions from different social groups, so male and female residents of different ages and from different community areas were invited to participate. Discussions on diets included only women who were responsible for preparing family meals. Based on information from the livelihood discussions, coping strategy exercises were carried out separately with 'better-off' and 'worse-off' residents as a proxy indicator for vulnerability to food insecurity (Horta et al. 2013). Participants classified households according to landholding areas, health, and age of household members, and access to cash income. In one village participants considered everybody to be doing equally well, so only one coping strategy discussion group was conducted.

Two trained facilitators led each discussion group in Spanish. When needed, community-based fieldwork coordinators helped with translation to local dialects. Discussions were recorded and free-hand notes were taken. Participation was voluntary and written consent was obtained from each participant after an explanation of the project's objectives, participants' rights, and data uses. The study obtained ethics approval from the University of Southampton's Ethics Committee (Ref 8717).

Thematic framework analysis was used to analyse combined free-hand notes and transcribed excerpts. Two general themes were established: (i) food scarcity scenarios and (ii) coping strategies. The first contained three categories according to the severity scenario established (Table 2). The second theme was divided into 14 categories, one for each coping strategy identified. These, in turn, contained sub-categories related to the livelihoods framework: capital endowments (financial, physical, social, cultural, and natural) and institutional factors.

Finally, coping strategies were grouped according to their association with different severity scenarios to ascertain patterns in capital mobilisation and institutional set-ups. A 'consensus ranking' approach was adopted (Maxwell and Caldwell 2008). Strategies were allocated to the severity scenario into which they were placed by the greatest number of discussion groups. If a strategy was equally allocated to two scenarios, the number of mentions in adjacent categories was used to determine the final classification (Table 3).

\section{Results}

\section{Local Diets}

Informants considered a meal satisfying and nourishing if it comprised fish or bushmeat, onions, peppers, and chilies, cooked as a soup, accompanied by cassava-based products (casaba, flat bread made from cassava flour, or fariña, roasted cassava flour), tucupi sauce (boiled cassava starch seasoned with salt, chilli, and spices), and fruit-based drinks, like 
Table 1 Number of discussion groups and informants per subject

\begin{tabular}{lllll}
\hline Exercise & $\begin{array}{l}\text { No. of discussion } \\
\text { groups }\end{array}$ & $\begin{array}{l}\text { Average length } \\
\text { (minutes) }\end{array}$ & $\begin{array}{l}\text { No. of } \\
\text { participants }\end{array}$ \\
\cline { 3 - 5 } & & Men & Women \\
\hline Livelihoods & 7 & 180 & 28 & 12 \\
Local diets & 7 & 225 & 0 & 38 \\
$\begin{array}{c}\text { Coping } \\
\text { strategies }\end{array}$ & 13 & 132 & 33 & 30 \\
\hline
\end{tabular}

caguanas (cassava starch mixed with fruit pulp), coladas (fruit pulp mixed with water), or chucula (pureed boiled bananas). The main agricultural contribution to local diets was cassava, which was typically cultivated across upland, lowland, and flood-plain chagras to ensure its availability across seasons. Residents stated that chilies and peppers were usually gathered from home gardens while perennial fruit plants, like bananas and pineapples, were usually grown in upland chagras.

Wild food contributions came mainly in the form of fish or bushmeat. The species caught for household consumption usually differed from those used for trade, like dorado fish or tapir. Most residents fish for small species such as pintadillo (Pseudoplatystoma spp), sábalo (Brycon sp.), and boquichico (Prochilodus sp.), whilst hunting focuses on medium-sized borugo rodents (Agouti taczanowskii), although white-lipped peccaries (Tayassu pecari) are also common. The wild fruits commonly harvested are palm fruits like chontaduro (Bactris gasipaes), canangucho (Mauritia flexuosa), milpesos (Oenocarpus bataua) and asai (Euterpe oleracea). Seasonality affects wild food availability. Residents reported a greater variety of small scaled-fish species and palm fruits during the dry season, when the abundance of palm fruits and low water levels were perceived to entice game to lowland areas, facilitating hunting.

Fishing, hunting, and foraging (collectively known as rebusque) are typically conducted on a daily basis. Aside from casabe and fariña, food is rarely stored due to a combination of factors: lack of electricity, warm and humid climatological conditions, and residents' preference for fresh produce. Meatsmoking techniques are mostly used as a culinary choice rather than a conservation measure. Easy-to-store non-indigenous products, such as rice and pasta (labelled 'white-people's food'), are occasionally added to meals.

\section{Food Insecurity in La Pedrera}

Participants from 'better-off' and 'worse-off' discussion groups reported that there had not been instances of starvation in the previous two decades and that residents, in general, 'always had something to eat.' However, they identified various factors that affected residents' capacity to obtain food in the quantity, variety, or quality desired (Table 2). First, they stated that hunting and fishing constituted unpredictable activities: while they generally managed to obtain food, they could not be sure about the amount or type of game or fish they would obtain on a daily basis. This uncertainty was perceived as more acute during adverse environmental conditions. Specifically, at the beginning of the rainy season many fishing and hunting grounds became flooded and small fish species dispersed in the floodplains, and game moved deeper into the forest, becoming more difficult to hunt. Friaje events (shortterm decreases in temperature, strong winds, and heavy rains) commonly occur between May and June, further limiting hunters' mobility and game availability. During the rainy-todry transition, households that fished in streams and ponds were negatively affected by the decreasing water levels. Extreme dry or wet seasons exacerbated these challenges.

A second factor affecting food availability concerned shortterm household labour unavailability due to travel or minor illness, which interrupted families' daily harvesting and rebusque activities. Finally, health emergencies, particularly those requiring constant care or hospital treatment, meant households could face mid- or long-term labour unavailability, affecting productive activities as well as generating financial pressures due to the need to purchase food to substitute natural resources and to cover travel and subsistence expenses if seeking treatment in cities. Deaths of adult family members affected households' access to food on a more permanent basis.

Building upon these descriptions, informants outlined different scenarios of growing inability to cover food needs. All except one group proposed a 3-tier severity gradient, which was thus adopted:

Table 2 Events leading to food scarcity reported by socioeconomic category

\begin{tabular}{lllll}
\hline Scarcity Event & \multicolumn{2}{l}{ No. of group discussions reporting a scarcity event } & & TOTAL $(n=13)$ \\
\cline { 2 - 5 } & Better-off & Worse-off & Mixed* \\
\hline Seasonal transition & 5 & 5 & 1 & 11 \\
Household-labour shortages & 6 & 6 & 1 & 13 \\
Health emergencies & 6 & 6 & 1 & 13 \\
\hline
\end{tabular}

*Single discussion group conducted in village reporting socioeconomic equality among residents 
Table 3 Coping strategies against food insecurity by socioeconomic category and severity scenario allocation

\begin{tabular}{|c|c|c|c|c|c|c|c|c|}
\hline \multirow[t]{2}{*}{ Coping Strategies (CS) } & \multirow[t]{2}{*}{$\begin{array}{l}\text { TOTAL } \\
(n=13)\end{array}$} & \multicolumn{3}{|c|}{$\begin{array}{l}\text { No. of groups reporting CS by } \\
\text { socioeconomic composition }\end{array}$} & \multicolumn{3}{|c|}{$\begin{array}{l}\text { No. of groups } \\
\text { assigning CS to a severity scenario }\end{array}$} & \multirow[t]{2}{*}{$\begin{array}{l}\text { Consensus } \\
\text { ranking }\end{array}$} \\
\hline & & Better-off & Worse-off & Mixed * & Low & Medium & High & \\
\hline $\begin{array}{l}\text { Travelling to uncommonly used } \\
\text { hunting and fishing grounds }\end{array}$ & 11 & 4 & 6 & 1 & 7 & 3 & 1 & \multirow[t]{3}{*}{ Low severity } \\
\hline Consuming less preferred wild foods & 6 & 2 & 3 & 1 & 4 & 1 & 1 & \\
\hline $\begin{array}{l}\text { Relying heavily on food borrowed from } \\
\text { neighbours and friends }\end{array}$ & 4 & 2 & 2 & - & 2 & 2 & 0 & \\
\hline Buying food on credit & 9 & 4 & 4 & 1 & 2 & 5 & 2 & \multirow[t]{5}{*}{ Medium severity } \\
\hline Rationing meal portions & 8 & 3 & 4 & 1 & 3 & 4 & 1 & \\
\hline Exchanging tools / products for food & 5 & 1 & 4 & - & 2 & 2 & 1 & \\
\hline Women and children to conduct rebusque activities & 4 & 2 & 2 & - & 0 & 3 & 1 & \\
\hline Eating same food every day (no meat or fish) & 4 & 2 & 2 & - & 1 & 2 & 1 & \\
\hline Financial donations from relatives & 9 & 3 & 5 & 1 & 1 & 2 & 6 & \multirow[t]{3}{*}{ High severity } \\
\hline Giving children priority & 8 & 3 & 4 & 1 & 2 & 1 & 5 & \\
\hline Hunting in conservation areas & 3 & 1 & 2 & - & 0 & 1 & 2 & \\
\hline
\end{tabular}

*Single discussion group conducted in village reporting socioeconomic equality among residents

1) Low-severity: short-term disruptions in the provision of animal protein, when residents could not obtain fish or bushmeat for a few days either because of unsuccessful hunting and fishing, weather conditions, or temporary household labour unavailability.

2) Medium-severity: a more prolonged period of limited access to animal protein, when diets became more reliant on farm produce. This responded to severe flooding or declining water levels or times when labour unavailability extended for a week or longer.

3) High-severity: Periods when households could no longer cover their food needs through traditional rebusque activities, commonly due to health crises. This resulted in poor diets, given residents' limited capacity to purchase food in markets due to scarce cash income and medical expenses, particularly if they travelled to cities to receive treatment.

\section{Local Responses to Growing Food Insecurity}

Participants detailed their responses to the food insecurity scenarios outlined (Table 3). 'Better-off' and 'worse-off' groups largely reported similar coping strategies. The most common coping behaviours comprised travelling farther to less frequently used hunting and fishing grounds, purchasing food on credit, asking for donations from relatives or friends, as well as rationing the frequency and amount of food consumed. Destitution-type strategies, such as selling assets, sending children away, or theft, were mentioned only once each and so were excluded from the analysis. The sole dissimilarity observed across socioeconomic groups consisted of an apparently greater reliance among 'worse-off' residents on exchanging tools or farm produce for food.
Low-severity food insecurity was associated with responses focused on managing locally available resources. These consisted of investing more time and energy in rebusque activities, with affected residents travelling farther than usual to reach fishing or hunting grounds; increasing consumption of wild foods that are less-preferred due to their taste, like mojojoy (Melolonthidae beetle grubs) and arriera ants (leafcutter ants, Attine tribe); or relying more heavily than usual on forms of collective consumption, such as sharing meals with or borrowing food from neighbours for a few days until rebusque activities could be resumed.

Under a medium-severity scenario, strategies shifted towards adopting rationing measures, mobilising additional household resources, and accessing external food sources. Rationing involved reducing the size of food portions and the variety of diets, with meals increasingly comprised of chagra produce (cassava, chilies, and fruits). The mobilisation of additional resources involved women and children engaging in rebusque activities, chiefly minor foraging and fishing activities. Accessing external food sources entailed trading cassava-based products for bushmeat or fish with villagers from other locations; conducting a form of tool 'rental' whereby households provided hunting or fishing gear to neighbours who then shared their catch or game; or trading farm produce with colonists, traders, or town residents in exchange for easyto-store processed items, like pasta or canned tuna. Residents also reported buying these items from traders on credit.

Responses to high-severity food insecurity were aimed at accessing cash income while adopting stringent forms of rationing. Rationing entailed children receiving larger meals (cassava and fruits) than adults. Informants reported, however, that adults rarely had to skip meals. Improving access to cash was mostly achieved via unconditional financial support from 
relatives or selling bushmeat in town markets. To obtain bushmeat, residents resorted to hunting mainly in community conservation areas where wildlife stocks are likely to be high.

\section{Coping Strategies and Forms of Capital Mobilisation}

In low-severity food insecurity scenarios, local responses relied chiefly on human, cultural, and social capital as inputs to access missing protein sources (Table 4). Human capital involved healthy household members walking for long distances to access distant fishing or hunting grounds whilst enduring mud, heat, humidity, and insects. Apart from shotguns, required physical capital was basic artisanal foraging and fishing equipment (e.g., harpoons or straw baskets). Alongside these material resources, informants highlighted the importance of various forms of knowledge and skills. These included being able to identify edible plants or fruits; fishing, hunting, and foraging techniques and skills; and recipes suitable for the food available. Additionally, informants considered it important to have a good understanding of the spiritual and ritual value of the landscape to avoid disturbing sacred areas when travelling. Social capital, in turn, helped residents to access fish and bushmeat through food-borrowing or mealsharing practices, embedded in traditional forms of reciprocity and redistribution. These involved continuous exchanges of favours and gifts among community households as expressions of closeness and a form of bonding. These forms of support did not demand reciprocity within specified timeframes or equivalent exchange. Food donations, instead, could be returned at an unspecified future occasion and in a different form (e.g., labour).

At an intermediate level of need, households used a more limited variety of capital endowments. Given the lack of labour availability, households resorted to mobilising women and children for rebusque activities. However, this mostly involved minor foraging and fishing since women and children were generally considered to lack the knowledge, skills, and physical strength of experienced male hunters and fishers. The repertoire of rebusque techniques and equipment was hence more limited. At this level of need, chagra produce became more central to diets, mainly cassava-based products and cultivated fruits that did not require labour-intensive harvesting.

Community members also engaged in different forms of trade. Households provided hunting or fishing gear to villagers who, in turn, shared the bushmeat or fish they caught. The loan periods varied according to the amount and type of food expected and relationship between parties. Another form of exchange involved exchanging cassava-based products with colonists, traders, and townspeople for easy-to-store 'white people's food' (e.g., canned tuna). Financial capital, moreover, appeared for the first time as a consideration for obtaining food, in the form of credit in local stores.
Although better and worse-off informants alike reported being able to obtain credit, the amount of food they could obtain depended on their monetary income. Only those with regular wages (e.g., village authorities) were in a position to cover their food needs through this strategy. For all these transactions, social capital was relevant but in the form of acquaintanceships with non-community members. Unlike the community-based mutually supportive relationships, transactions with outsiders required negotiating the conditions of return or repayment, particularly in the case of nonindigenous products with a known monetary value.

At the highest level of need, the range of equipment, knowledge, and skills required for hunting were more limited than in previous scenarios because hunting was now specifically aimed at game with market value, such as agouties and peccaries. If possible, hunting was conducted in wildlife-rich conservation areas so that human capital investments (time and energy) were not too demanding. Social capital was key for dealing with severe shocks as well, since having a good relationship with traders was valuable for bushmeat commercialisation. In addition, having relatives in urban areas, with easier access to cash income, was considered advantageous to provide financial support to families facing health emergencies.

\section{Coping Strategies at the Institutional Interface}

Villagers' responses to varying levels of food insecurity required them to engage with different normative structures. When facing short-term food shortages, coping strategies were guided by community-based rules. These included residents' rights to exploit the natural resources within the community's territory and their obligations to respect the conservation areas delimited by local management plans. In addition, traditions of reciprocity and gift giving enabled food sharing and borrowing practices; while the extraction of natural resources largely followed traditional gender-based roles, with major fishing and hunting considered male activities.

Under a medium-severity scenario, residents dealt with a mix of local and external rules. At the community level, a strong reliance on farm produce for home consumption underscored the importance of traditional entitlements to chagras. Informants' observation that they 'always had something to eat' centred on the expectation that all residents, independently of their wealth, would have at least one chagra and that the cultivation of perennial crops would ensure a basic but constant access to food that could be complemented through foraging and food-sharing practices. Complementary response mechanisms, however, relied on equivalent exchanges, rental schemes, and purchases on credit, which entailed dealing with market-economy considerations. Informants then experienced difficulties in negotiating satisfactory terms of exchange. In a market context, fellow- 


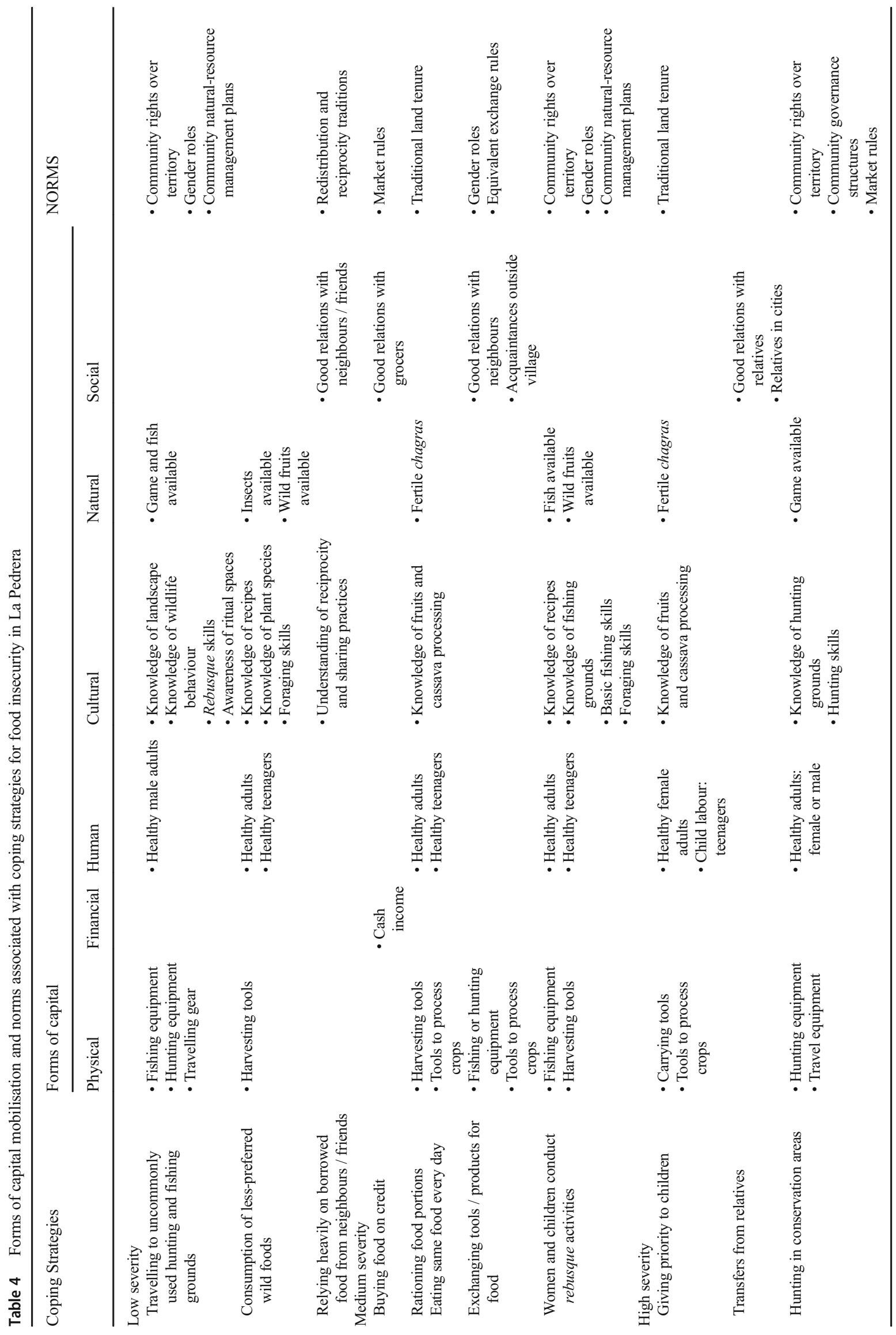


indigenous residents became competitors, each of them offering similar produce (fish, fruits, and cassava-based products). Moreover, seasonality effects on traditional production functions hindered a favourable integration of traditional productive activities into market transactions since periods of 'abundance' implied low market prices. Finally, market prices were also affected by a range of external factors, such as fluctuations in fuel prices and inflation that were difficult for residents with limited access to mass media to track. Furthermore, some difficulties were specific to women, who reported being offered lower prices than men and facing male traders' reluctance to engage in price negotiations with them.

This combination of local and external norms was also observed in high-severity scenarios. When food insecurity followed health emergencies, residents relied upon their access to chagras for basic sustenance and their rights to exploit forest areas to obtain bushmeat for sale. If hunting was to take place in conservation areas, village authorities needed to be consulted. Residents then requested a permit by detailing the nature of the emergency and the amount of resources required. Once bushmeat was obtained, however, villagers faced the challenge of market negotiations. Informants explained that bushmeat sales were unlikely to raise substantive cash due to market conditions. Since the town-market was the only one accessible for most villagers and only a handful of traders operated there, prices paid were regularly pushed down, whilst transportation costs were high for local standards. Informants' descriptions of traders as 'greedy' or 'abusive' reflected their difficulties in overcoming these hurdles.

\section{Discussion}

Depictions of diets, food shortages, and coping behaviours in La Pedrera highlight three general features of the socioecological dynamics of food insecurity among subsistence indigenous communities in Amazonia. First, as reported in nutritional studies in similar socio-ecological settings, residents have adapted their daily practices to the surrounding biodiversity, with wild foods constituting a central part of their diets (Piperata et al. 2011; Roche et al. 2007; Sunderland et al. 2013). This dependency on wild foods, however, exposes residents to constant fluctuations in food access. Rebusque activities are inherently unpredictable and cannot guarantee steady access to quality foods, even if fishers and hunters possess substantive expertise and operate under favourable climate conditions. In addition, communities are vulnerable to adverse climate events, such as flooding and friaje events, which reduce the availability of wild foods indirectly by shaping wildlife migration patterns, and directly by restricting peoples' physical access to fishing and hunting grounds. Traditional livelihoods are particularly vulnerable to idiosyncratic stressors as well, in the form of labour unavailability. Since rebusque is conducted on a daily basis, any labour restrictions due to illness or forced absence have a rapid impact on household diets, with health crises potentially compromising a household's long-term capacity to satisfy its food needs if they result in physical disability, chronic illness, or death. Adult men are critical to this dynamic, since they are customarily responsible for major fishing and hunting activities.

Second, despite these forms of vulnerability, there is no evidence that adverse climate conditions, labour unavailability, or health emergencies lead to hunger or destitution in the region, signifying that local food systems are resilient enough to avoid severe food insecurity (Davies 1993; Ellis 2003). Whilst institutionalised food-sharing practices act as a mitigating measure during short-term food scarcity events in La Pedrera, regular access to food is largely achieved through institutionalised community-based norms guiding farmland management. Traditional cultivation systems, based on shifting slash-andburn agriculture, intercropping of perennial crops, cultivation of upland chagras, and home gardening, ensure access to staple crops and fruits all-year-round; at the same time land-tenure arrangements based on community membership and reciprocal free-labour schemes allow residents to cultivate chagras regardless of their wealth. Previous studies have highlighted the role forest resources play as insurance mechanisms (McSweeney 2004; Pattanayak and Sills 2001; Takasaki et al. 2004). Our results suggest that in comparable socio-ecological settings, NTFPs mostly play a complementary role during food insecurity events. That is, they help to enrich agriculture-dependent diets by providing alternative protein sources (e.g., insects) and a source of cash (bushmeat) to purchase easy-to-store processed foods. Moreover, it can be argued that although NTFP sales typically render low returns, as reported here and elsewhere (Takasaki et al. 2004; van Vliet et al. 2014), they constitute a practical strategy for dealing with food insecurity in large part because residents are already able to cover their most basic needs through chagra produce.

Thirdly, as reported for other forest-dwelling communities, La Pedrera residents' responses to stressors and shocks show a strong reliance on natural capital (Harvey et al. 2014; F. Paumgarten et al. 2018; Sunderland et al. 2013). The manner in which it is used, however, varies according to degree of severity. At lower levels of severity, residents can rely upon a wide range of wild foods, like insects and wild fruits, to cope with food insecurity. During emergencies, their focus turns exclusively to game. This narrowing down of options indicates a gradual change in the type of food-provisioning activities residents conduct, which shift from non-monetary collective-consumption and sharing practices to equivalent exchange and trade. That is, under severe pressure, indigenous peoples centre on the exchange-value of natural resources as commodities. In this manner, while the coping mechanisms reported under severe food insecurity may not indicate destitution, they still reflect a failure in the capacity of traditional 
livelihoods to cover residents' food needs. Residents then are compelled to move away from their community context into the wider economy. This constitutes a major challenge since, aside from being small economic actors, villagers usually lack extended good connections with town-traders and the knowledge and skills relevant to market exchanges.

These three overall features help to identify key sustainability challenges associated with natural ecosystems' contributions to the food systems of subsistence indigenous peoples. It is apparent that although traditional adaptations to the environment and the well-preserved state of forest areas prevent severe food insecurity in La Pedrera, it is doubtful that these can ensure food security understood as regular access to sufficient nutritious foods for normal growth and a healthy life (FAO 2017). Certainly, nutritional evidence indicates that traditional food systems can provide healthy and balanced diets (Kuhnlein et al. 2013; Roche et al. 2007). However, fluctuations in the volume and quality of foods consumed constitute a persistent feature given the systems' sensitivity to labour shortages and climatic events. A 2014 census in the corregimiento, for instance, found that $47.5 \%$ of households reported having been unable to consume their preferred meals at some point during the dry season (Handini 2016). Historical hydrological data indicate frequent above-average dry and wet seasons (2005 and 2011; 2004 and 2012, respectively) (IDEAM 2015). At the same time, the labour-intensive lifestyles of forest dwelling subsistence farmers have elevated energy requirements. A parallel study in the region noted that subsistence livelihoods rendered daily energy requirements between 3200 and $5900 \mathrm{cal}$, depending on the season (Duran et al. 2016). Temporary incapacity to achieve such caloric intakes may have significant implications for residents' health, particularly vulnerable groups like infants and pregnant and lactating women (Moore 2004).

Prospective environmental change scenarios raise additional concerns. Presently, the rich biodiversity observed in La Pedrera buffers fluctuations in food access, so that periods of scarcity are usually short-term and a range of less-preferred wild-foods are customarily at hand when favoured options are not available. However, this regional ecological equilibrium can be affected by drivers of environmental change operating at a larger scale (Pramova et al. 2012; UNEP 2009). For instance, climatological assessments for the entire Amazon have recorded an intensification and lengthening of dry seasons (Joetzjer et al. 2013) and conservation models report that biodiversity-rich areas can face extinction threats originating elsewhere due to knock-on effects from deforestation (Soares-Filho et al. 2006).

In this regard, examining the interdependency between natural and other forms of capital acquires particular significance since the latter condition people's capacity to maximise the benefits they accrue from ecosystems. Human capital is critical, since natural resources are only accessed through a healthy labour force in subsistence-economies. In Amazonia, however, indigenous populations face many threats to their health. They customarily lack of access to health services and sanitation infrastructure, pursue livelihoods that expose them to natural hazards and accidents, and reside in endemic areas for tropical diseases, such as malaria and dengue fever (Takasaki et al. 2004; UNEP 2009). Unless governments invest in relevant public services, indigenous peoples' food security could be threatened not only by frequent short-term labour losses but also by the potential transformation of minor illnesses into health emergencies due to the absence of treatment. Moreover, endemic diseases can reduce peoples' capacity to absorb nutrients from food (FAO 2016). Uncertainty regarding to the impact of climate change on vector-borne diseases (Brondízio et al. 2016) adds a sense of urgency to integrating human capital considerations in conservation debates around food security.

Social and cultural capital considerations equally emerge as important mediators of natural resources. Institutionalised forms of collective consumption help villagers to access scarce food items through friends and neighbours (Kuhnlein et al. 2013; Van der Hammen 1992). Equally, good environmental knowledge and rebusque skills are essential to ensure access to a wide range of wild foods (Paumgarten and Shackleton 2011; Reyes-García et al. 2008). Under severe food insecurity scenarios, however, these capitals appear insufficient since residents are forced to look for resources in non-indigenous settings. Discussions around the sustainability of nature-based strategies would thus benefit from expanding their assessments beyond the local context, which traditionally focus on household-level economic indicators (McSweeney 2004; Takasaki et al. 2004) or individual-level nutrition measures (Godoy et al. 2005; Piperata et al. 2011). Communitybased forms of support have clear limitations, since the resources required to fulfil people's nutritional requirements may not available locally or the level of need may be too high for local resources to accommodate. In these circumstances, it is connections with external actors - known as 'bridging' social capital - that offer poor people the potential for overcoming crises (Bebbington et al. 2006). Access external resources also appears central to enhancement of people's cultural capital. Limited access to market information constitutes an economic barrier that is not only relevant to marketoriented farmers but also to subsistence indigenous households facing worsening food insecurity (van Vliet et al. 2014).

The presence of structural barriers raises additional questions about the extent to which forest products can provide adequate support to subsistence-oriented indigenous groups in case of severe food insecurity. On the one hand, indigenous communities' adaptations to their environment favour the accumulation of capital endowments of limited value in the market context. Expressions of human capital, for instance, centre on physical strength; physical capital mostly consists of artisanal equipment; labour is accessed through support networks; and 
residents have no ownership over their landholdings (Fontaine 2008; Van der Hammen 1992). Consequently, the very factors that allow a household to successfully pursue traditional livelihoods also place it at a disadvantage within the wider political economy (Rigg 2007). On the other hand, the geographical isolation that protects communities from biodiversity losses often favour market conditions that exacerbate unfavourable negotiating positions (Rigg 2007; van Vliet et al. 2014). As observed in our study, fishers and hunters are forced to compete against each other, face substantial transportation costs, and trade in a reduced number of markets as well as with buyers who are then able to control prices. These barriers contribute to undermining the environmental sustainability of nature-based nutritional insurance mechanisms. If ongoing environmental change negatively affects livelihoods, this might generate increasing pressures on wildlife as villagers turn to bushmeat trade to boost their income (van Vliet et al. 2014).

\section{Limitations}

There are constraints associated with the participatory methodology we used in this study. First, while the research team tried to include testimonies from multiple sources, participants did not constitute a statistically representative sample. As previously noted, the study accounted for gender and socioeconomic differences and reported only those findings consistently found across discussion groups. However, it remains uncertain if hidden forms of bias may have affected participation or data-elicitation (e.g., friendship networks) (Mosse 1994). This limits the generalisability of our results to the entire region.

Our methods, in addition, did not utilise standard food insecurity measures, such as stunting or caloric intake (FAO 2017). Participatory approaches instead centre on local forms of knowledge and representations (Schreckenberg et al. 2016). Thus, we examined food security as perceived and understood by participants themselves. The highly-contextualised nature of depictions, however, affected the possibility of integrating our results into technical nutritional assessments. Nevertheless, our qualitative results identified a wide range of human-nature relationships that can inform future quantitative food insecurity assessments. Moreover, they also provide contextual data that help to explain indigenous populations' policy preferences regarding conservation and nutrition (Kuhnlein et al. 2013).

Finally, participatory appraisals have been conceived to render detailed accounts of living conditions in a short timeframe (Mosse 1994). An associated drawback is that they are unable to generate the same level of indepth understanding of knowledges and perceptions as ethnographic approaches. Reported narratives of scarcity events and coping strategies hence provide an initial portrayal of a complex and dynamic process. Longerterm research efforts could provide additional insights. Similarly, the focus on residents' testimonies constrained our understanding of interactions with external actors. Future examinations would benefit from direct observation of indigenous peoples' interactions outside their communities (e.g., market transactions).

\section{Conclusion}

This case study illustrates the challenges of ensuring sustainable natural resource-based contributions to prevent food insecurity among rural indigenous populations in Amazonia. Results show that natural ecosystems are unlikely to provide sufficient protection even under favourable conditions given variable climatic conditions, unpredictability of rebusque practices, and local food systems' sensitivity to labour losses. Moreover, it emerged that natural resource-based strategies to deal with severe food insecurity are realised outside the local socio-ecological setting under unfavourable terms of exchange. Market integration in the region is associated with forest-degradation and deforestation (Ortiz et al. 2013; UNEP 2009), increasing consumption of sugar and fats (Piperata et al. 2011; van Vliet et al. 2015; Welch et al. 2009), and losses of environmental knowledge and social institutions (Reyes-García et al. 2008; Rigg 2007). Furthermore, indigenous communities may be reluctant to adopt strategies that depart from their traditional livelihoods given their past experiences with cultural, economic, and biodiversity losses (Kuhnlein et al. 2013). Further efforts are thus required to examine how the socio-ecological dynamics of food insecurity operate across different combinations of market integration and natural resource management strategies (e.g., eco-tourism or ago-forestry) (Poppy et al. 2014; Sunderland et al. 2013). As discussed, such assessments cannot be confined to environmental, nutritional, or economic measures. Careful attention should be given to the social structures that allow for the incorporation of natural resources into local diets and promote resilience of the local ecosystem. To be viable, any ensuing policy decisions must incorporate Amazon indigenous populations' own understandings of food insecurity conditions.

Acknowledgements We thank Erwin Palacios (Conservation International) for coordinating fieldwork and the Association of Indigenous Authorities of La Pedrera and villagers for granting us access to their communities. We are grateful to Daniel Giraldo, Sandra Cardona, Catalina Angel, Sara Ramirez-Gomez, and Lina Gallego for collecting field-data, and Charlie Shackleton for his inputs to early drafts of the text. 
Funding The study was conducted under the 'Attaining Sustainable Services from Ecosystems using Trade-off Scenarios' project (NEJ002267-1), funded by the Ecosystem Services for Poverty Alleviation program (ESPA).

Data Availability The data analysed for the study are available from the corresponding author on request.

\section{Compliance with Ethical Standards}

Conflict of Interest The authors declare that they have no conflict of interest.

Open Access This article is distributed under the terms of the Creative Commons Attribution 4.0 International License (http:// creativecommons.org/licenses/by/4.0/), which permits unrestricted use, distribution, and reproduction in any medium, provided you give appropriate credit to the original author(s) and the source, provide a link to the Creative Commons license, and indicate if changes were made.

\section{References}

Arroyo-Kalin, M. (2012). Slash-burn-and-churn: Landscape History and Crop Cultivation in Pre-Columbian Amazonia. Quaternary International 249: 4-18.

Bebbington, A., Woolcock, M., Guggenheim, S. E., and Olson, E. (2006). The Search for Empowerment: Social Capital as Idea and Practice at the World Bank, Kumarian Press, Washington DC.

Berman, R., Quinn, C., and Paavola, J. (2012). The Role of Institutions in the Transformation of Coping Capacity to Sustainable Adaptive Capacity. Environmental Development 2: 86-100.

Brondízio, E. S., de Lima, A. C., Schramski, S., and Adams, C. (2016). Social and Health Dimensions of Climate Change in the Amazon. Annals of Human Biology 43(4): 405-414.

Cruz-Garcia, G. S., Sachet, E., Vanegas, M., and Piispanen, K. (2016). Are the Major Imperatives of Food Security Missing in Ecosystem Services Research? Ecosystem Services 19: 19-31.

Davies, S. (1993). Are Coping Strategies a Cop Out. IDS Bulletin 24(4): 60-72.

Departamento Administrativo Nacional de Estadistica - DANE (2011). Estimaciones de Poblacion 1985-2005 y Proyecciones de Poblacion 2005-2020. Retrieved from https://www.dane.gov.co/files/ investigaciones/poblacion/proyepobla06_20/Municipal_area 1985-2020.xls. Accessed 11 Apr 2017.

Duran, Z., Arguello, H., and Tapasco, J. (2016). A Methodological Approach for the Non-Monetary Valuation of Ecosystem Services in Three Communities of the Colombian Amazon. Agronomía Colombiana 34(1): 109-120.

Ellis, F. (2003). Human Vulnerability and Food Insecurity: Policy Implications, Overseas Development Institute, London.

Eriksen, S. H., Brown, K., and Kelly, P. M. (2005). The Dynamics of Vulnerability: Locating Coping Strategies in Kenya and Tanzania. The Geographical Journal 171(4): 287-305.

FAO (2016). The State of Food and Agriculture: Climate Change, Agriculture and Food Security. Rome: FAO.

FAO (2017). The State of Food Security and Nutrition in the World: Building Resilience for Food and Food Security, FAO, Rome.

Ferse, S. C., Glaser, M., Neil, M., and Máñez, K. (2014). To Cope or to Sustain? Eroding Long-Term Sustainability in an Indonesian Coral Reef Fishery. Regional Environmental Change 14(6): 2053-2065.
Fontaine, L. (2008). Paroles d'échange et règles sociales chez les indiens Yucuna d'Amazonie colombienne, L'Harmattan, Paris.

Godoy, R., Reyes-García, V., Vadez, V., Leonard, W., Huanca, T., et al (2005). Human Capital, Wealth, and Nutrition in the Bolivian Amazon. Economics \& Human Biology 3(1): 139-162.

Handini, W. (2016). The relationship between coping strategies and households' wellbeing in La Pedrera, Amazonas (Colombia). Unpublished master's thesis. University of Southampton, Southampton, United Kingdom.

Harvey, C. A., Rakotobe, Z. L., Rao, N. S., Dave, R., Razafimahatratra, H., et al. (2014). Extreme Vulnerability of Smallholder Farmers to Agricultural Risks and Climate Change in Madagascar. Phil. Trans. R. Soc. B, 369 (1639), 20130089.

Horta, B. L., Santos, R. V., Welch, J. R., Cardoso, A., dos Santos, J., et al (2013). Nutritional Status of Indigenous Children: Findings from the first National Survey of Indigenous People's Health and Nutrition in Brazil. International Journal for Equity in Health 12: 23.

Instituto de Hidrología, Meteorología y Estudios Ambientales de Colombia - IDEAM (2014a). Colombia. Precipitación total anual y mensual de la estación Vasquez Cobo, Leticia. Retrieved from http:/www.ideam.gov.co/documents/24155/123683/01-51_D_ Precipitaci\%C3\%B3n_ciudades_4_FI.xls/ad2532be-6767-41bea984-6c5dfb07242c. Accessed 22 Apr 2018.

Instituto de Hidrología, Meteorología y Estudios Ambientales de Colombia - IDEAM (2014b). Colombia. Temperatura media mensual del aire registrada en la estación Vásquez Cobo, Leticia. IDEAM. Retrieved from http://www.ideam.gov.co/documents/ 24155/123683/11-85_D_Temperatura_media_4_FI.xls/71bdb6ef08c1-43b0-a65d-983d2b840c87. Accessed 22 Apr 2018.

Instituto de Hidrología, Meteorología y Estudios Ambientales de Colombia - IDEAM (2015). Estudio Nacional del Agua 2014. Bogotá: IDEAM.

Joetzjer, E., Douville, H., Delire, C., and Ciais, P. (2013). Present-Day and Future Amazonian Precipitation in Global Climate Models: CMIP5 versus CMIP3. Climate Dynamics 41(11-12): 2921-2936.

Kuhnlein, H. V., Erasmus, B., Spigelski, D., and Burlingame, B. (eds.) (2013). Indigenous Peoples' Food Systems \& Well-Being: INTERVENTIONS \& policies for Healthy Communities, FAO, Rome.

Marengo, J. A., Borma, L. S., Rodriguez, D. A., Pinho, P., Soares, W. R., and Alves, L. (2013). Recent Extremes of Drought and Flooding in Amazonia: Vulnerabilities and Human Adaptation. American Journal of Climate Change (02, 02): 87-96.

Maxwell, D., and Caldwell, R. (2008). The coping strategies index: Field methods manual. Feinstein International Center.

Maxwell, D., Caldwell, R., and Langworthy, M. (2008). Measuring Food Insecurity: Can an Indicator Based on Localized Coping Behaviors be Used to Compare Across Contexts? Food Policy 33(6): 533-540.

McSweeney, K. (2004). Forest Product Sale as Natural Insurance: The Effects of Household Characteristics and the Nature of Shock in Eastern Honduras. Society and Natural Resources 17(1): 39-56.

Moore, S. E. (2004). Comparative Analysis of Patterns of Survival by Season of Birth in rural Bangladeshi and Gambian populations. International Journal of Epidemiology 33(1): 137-143.

Mosse, D. (1994). Authority, Gender and Knowledge: Theoretical Reflections on the practice of participatory rural appraisal. Development and Change 25(3): 497-526.

Ojeda, G., Ordóñez G., M., and Ochoa, L. H. (Eds.). (2011). Colombia: Encuesta nacional de demografía y salud, 2010. Bogotá: Profamilia.

Ortiz, R., Nowak, A., Lavado, A., and Parker, L. (2013). Food Security in Amazonia. Cali: International Center for Tropical Agriculture.

Pattanayak, S. K., and Sills, E. O. (2001). Do Tropical Forests Provide Natural Insurance? The Microeconomics of Non-Timber Forest Product Collection in the Brazilian Amazon. Land Economics 77(4): 595-612. 
Paumgarten, F., and Shackleton, C. M. (2011). The Role of non-Timber Forest Products in Household Coping Strategies in South Africa: The Influence of Household Wealth and Gender. Population and Environment 33(1): 108-131.

Paumgarten, F., Locatelli, B., and Witkowski, E. T. (2018). Wild Foods: Safety Net or Poverty Trap? A South African Case Study. Human Ecology 46(2): 183-195.

Piperata, B. A., Ivanova, S. A., Da-gloria, P., Veiga, G., Polsky, A., et al (2011). Nutrition in Transition: Dietary Patterns of Rural Amazonian Women During a Period of Economic Change. American Journal of Human Biology 23(4): 458-469.

Poppy, G. M., Chiotha, S., Eigenbrod, F., Harvey, C. A., Honzák, M., et al (2014). Food Security in a Perfect Storm: Using the Ecosystem Services Framework to Increase Understanding. Philosophical Transactions of the Royal Society B: Biological Sciences 369(1639): 20120288.

Powell, B., Thilsted, S. H., Ickowitz, A., Termote, C., Sunderland, T., and Herforth, A. (2015). Improving Diets with Wild and Cultivated Biodiversity from Across the Landscape. Food Security 7(3): 535-554.

Pramova, E., Locatelli, B., Djoudi, H., and Somorin, O. (2012). Forests and Trees for Social Adaptation to Climate Variability and Change. WIREs: Climate Change 3(6).

Ramirez-Gomez, S. O., Torres-Vitolas, C. A., Schreckenberg, K., Honzák, M., Cruz-Garcia, G., et al (2015). Analysis of Ecosystem Services Provision in the Colombian Amazon Using Participatory Research and Mapping Techniques. Ecosystem Services 13: 93-107.

Reyes-García, V., McDade, T., Vadez, V., Huanca, T., Leonard, W. R., et al (2008). Non-Market Returns to Traditional Human Capital: Nutritional Status and Traditional Knowledge in a Native Amazonian Society. The Journal of Development Studies 44(2): 217-232.

Richardson, R. B. (2010). Ecosystem Services and Food Security: Economic Perspectives on Environmental Sustainability. Sustainability 2(11): 3520-3548.

Rigg, J. (2007). An Everyday Geography of the Global South, Routledge, London.

Roche, M. L., Creed-Kanashiro, H. M., Tuesta, I., and Kuhnlein, H. V. (2007). Traditional food system provides dietary quality for the Awajún in the Peruvian Amazon. Ecology of Food and Nutrition 46(5-6): 377-399.

Sánchez-Cuervo, A. M., Aide, T. M., Clark, M. L., and Etter, A. (2012). Land Cover Change in Colombia: Surprising Forest Recovery Trends between 2001 and 2010. PLoS ONE 7(8): e43943.

Schreckenberg, K., Torres-Vitolas, C., Willcock, S., Shackleton, C., Harvey, C., et al. (2016). Participatory Data collection for
Ecosystem Services Research a Practitioner's Manual (Report). Ecosystem Services for Poverty Alleviation (ESPA). Retrieved from http://spiral.imperial.ac.uk/handle/10044/1/52995. Accessed 16 Sept 2018.

Shackleton, C., and Shackleton, S. (2004). The importance of NonTimber Forest Products in Rural Livelihood Security and as Safety Nets : A Review of Evidence from South Africa. South African Journal of Science 100(11-12): 658-664.

Scoones, I. (1998). Sustainable Rural Livelihoods: A Framework for Analysis, IDS Working Paper 72, Brighton: IDS.

Soares-Filho, B. S., Nepstad, D. C., Curran, L. M., Cerqueira, G., Garcia, R., et al (2006). Modelling Conservation in the Amazon basin. Nature 440(7083): 520-523.

Sunderland, T. C. H., Powell, B., Ickowitz, A., Foli, S., Pinedo-Vasquez, M., et al. (2013). Food security and nutrition: The role of forests. Center for International Forestry Research.

Takasaki, Y., Barham, B. L., and Coomes, O. T. (2004). Risk Coping Strategies in Tropical forests: Floods, Illnesses, and Resource Extraction. Environment and Development Economics 9(02): 203-224.

United Nations (2015). Transforming Our World: The 2030 Agenda for Sustainable Development (no. A/RES/70/1). New York: UN.

United Nations Environment Programme - UNEP (2009). Environment outlook in Amazonia geo-Amazonia. Panama City: UNEP.

Van der Hammen, M. C. (1992). El manejo del mundo: naturaleza y sociedad entre los Yukuna de la Amazonía Colombiana., TROPENBOS, Bogotá.

van Vliet, N., Mesa, M. P. Q., Antia, D. C., Morsello, C., Adams, C., et al. (2014). Bushmeat in the tri-frontier region of Brazil, Peru and Colombia: Demise or persistence? (Vol 118). CIFOR.

van Vliet, N., Quiceno-Mesa, M. P., Cruz-Antia, D., Tellez, L., Martins, C., et al (2015). From Fish and Bushmeat to Chicken Nuggets: The Nutrition Transition in a Continuum from Rural to Urban Settings in the Tri Frontier Amazon Region. Ethnobiology and Conservation (0): 4.

Welch, J. R., Ferreira, A. A., Santos, R. V., Gugelmin, S., Werneck, G., and Coimbra, C. Jr. (2009). Nutrition Transition, Socioeconomic Differentiation, and Gender Among Adult Xavante Indians, Brazilian Amazon. Human Ecology 37(1): 13-26.

Yin, R. K. (2008). Case Study Research: Design and Methods, SAGE, Los Angeles.

Publisher's Note Springer Nature remains neutral with regard to jurisdictional claims in published maps and institutional affiliations. 